\title{
Calculation of Constrained Stress in Expansive Mortar with a Composite Creep Model
}

\author{
Hyeonggil Choi ${ }^{1}$ and Bongsuk Cho ${ }^{2}$ \\ ${ }^{1}$ Graduate School of Engineering, Muroran Institute of Technology, 27-1 Mizumoto-cho, Muroran, Hokkaido 080-8585, Japan \\ ${ }^{2}$ Slag Utilization Research Team, Research Institute of Industrial Science \& Technology, 32 Hyoja-dong, Nam-ku, \\ Pohang 37673, Republic of Korea \\ Correspondence should be addressed to Bongsuk Cho; chos8@hanmail.net
}

Received 26 February 2016; Revised 11 May 2016; Accepted 29 May 2016

Academic Editor: Antônio G. de Lima

Copyright (C) 2016 H. Choi and B. Cho. This is an open access article distributed under the Creative Commons Attribution License, which permits unrestricted use, distribution, and reproduction in any medium, provided the original work is properly cited.

\begin{abstract}
The creep phenomenon of hardening cement paste mixed with an expansive additive was modeled by considering the creep performance of hydration products of cement and expansive additive. A new composite model that is appropriate for particle conditions is proposed by considering the balance of the hydration products of cement and expansive additive and the stress redistribution phenomenon of hydration products newly generated by the progress of hydration. The creep of mortar and concrete mixed with the expansive additive was evaluated using a composite model of the paste and aggregate. Under the assumption that the modeled creep deformation is proportional to the stress and the gel volume of the hydration products, which allows the law of superposition to be applied, the distribution stress was predicted by applying the step-by-step method at each time increment. By predicting the maximum tensile stress applied to an inner steel ring through a creep analysis based on the measured deformation of the inner steel ring, it is possible to predict the stress progression with age to some degree.
\end{abstract}

\section{Introduction}

Stress occurs within concrete under various constraints. If this stress exceeds the allowable limit, cracks may be generated in the concrete. Such cracks facilitate the penetration of salt or acid, which leads to the corrosion of the internal rebar and in turn decreases the internal strength and durability of the structures $[1,2]$. In particular, cracks that form before the public use of the structure may initiate functional or aesthetic degradation even below the allowable crack width of the design. Thus, the demand to reduce shrinkage cracks in reinforced concrete structures has increased in recent years [1-3]. Concrete experiences strain under a certain stress condition called creep; this decreases the stress, which must be taken into account. Hence, identifying the creep performance is crucial to calculating the stress in concrete and should not be overlooked during the design process [4-6]. Under these circumstances, the use of expansive additives has increased as a countermeasure against cracking due to concrete shrinkage, and the material characteristics of concrete mixed with expansive additives have been widely studied [7-11]. However, only a few studies have focused on creep. Thus, the available literature is insufficient for a quantitative evaluation of the creep performance.

In this study, the creep of hardening cement paste mixed with an expansive additive was modeled to estimate the constrained stress of expansive mortar and calculate changes in this stress.

\section{Composite Creep Modeling}

2.1. Composite Creep Model of Hardening Cement Paste Mixed with Expansive Additive. The creep of hardening cement paste mixed with an expansive additive $[12,13]$ was modeled by following the creep model for normal concrete of Lokhorst and van Breugel [14] and Maruyama [15]. Figure 1 shows the composite creep model of the hardening cement paste mixed with expansive additive. In this model, the hydration product of the expansive additive inside the hardening paste provides resistance and balance against the hydration product of the 


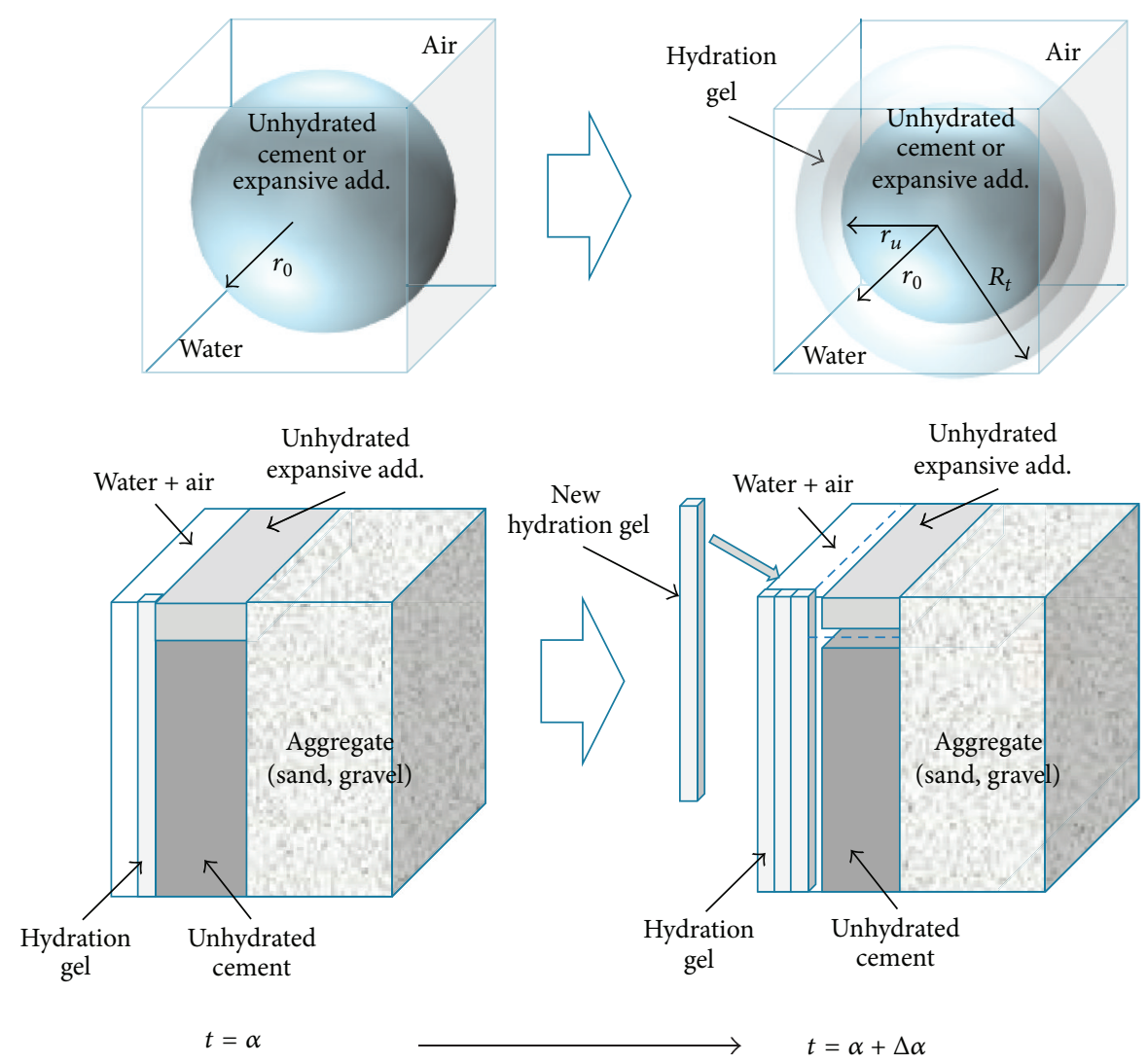

FIgURE 1: Composite creep model of the cement paste mixed with expansive additive.

cement. Only the cement and expansive additive hydration products are assumed to exhibit creep, and the creep properties and conditions of these hydration products are assumed to be uniform temporally and spatially. The model assumes that the unhydrated cement and expansive additive are solids with a uniform elastic modulus and that the moisture inside the capillary does not share the burden of stress.

The cement paste mixed with expansive additive consists of water, hydration products, unhydrated cement, and unhydrated expansive additive, as shown in Figure 1. During the hydration process, the radius of the original cement and expansive additive particle $r_{0}$ decreases to $r_{u}$ with a decreasing amount of water. At the same time, the amount of hydration products increases, which increases the radius of the outermost hydration product $R_{t}$. The figure shows the hydration products generated during this process in the form of an element of a bar based on the work of Lokhorst and van Breugel [14] and Maruyama et al. [15, 16]. The inserted elements of hydration products are assumed to increase because of the increase in the outermost radius $R_{t}$, and an element is inserted every time the contact area $A_{c}$ changes by $1 \%$. Here, $A_{c}$ was assumed to be a parameter for the formation of the paste structure mixed with expansive additive, and it depends on the hydration rate. The existing concept of the contact area according to the Computational Cement Based Material (C-CBM) model [15] was proposed by Maruyama and is introduced and modeled here. As hydration progresses, the contact area between particles increases because of the collision between particles. $A_{c}$ depends on the radius of the hydration products and can be expressed as follows $[12,15]$ :

Case of $0.5 \leq R_{t}<\sqrt{2} / 2$ :

$$
A_{c}=\pi\left(R_{t}^{2}-0.5^{2}\right) \text {. }
$$

Case of $\sqrt{2} / 2 \leq R_{t}<\sqrt{3} / 2$ :

$$
\begin{aligned}
A_{c} & =8\left[\frac{1}{2}\left(R_{t}^{2}-0.5^{2}\right)\right. \\
& \cdot\left(\frac{\pi}{4}-A \cos \left(\frac{0.5}{\sqrt{R_{t}^{2}-0.5^{2}}}\right)\right) \\
& \left.+0.25 \sqrt{R_{t}^{2}-0.5}\right] .
\end{aligned}
$$

Similar to previous studies, the outermost radius $R_{t}$ can be obtained as follows $[13,15]$ :

$$
R_{t}=(1+(V-1) \alpha)^{1 / 3} \cdot r_{0} .
$$

The volume increase rate $V$ of cement has been defined as 1.9-2.2 in previous studies [17]. Based on this range, $V$ was set 
TABLE 1: Mineral composition of cement and expansive additive [12].

\begin{tabular}{lcccccccc}
\hline \multirow{2}{*}{ Type } & \multicolumn{4}{c}{ Mineral composition (\%) } \\
& $\mathrm{SiO}_{2}$ & $\mathrm{Fe}_{2} \mathrm{O}_{3}$ & $\mathrm{Al}_{2} \mathrm{O}_{3}$ & $\mathrm{CaO}$ & $\mathrm{SO}_{3}$ & $\mathrm{MgO}$ & $\mathrm{Total}$ & $\mathrm{f}-\mathrm{CaO}$ \\
\hline Ordinary Portland cement & 21.0 & 2.9 & 5.2 & 64.4 & 2.3 & 1.2 & 97.0 & - \\
Expansive additive & 1.0 & 0.8 & 7.2 & 70.6 & 18.5 & - & 98.1 & 49.8 \\
\hline
\end{tabular}

to 2.0 in this study by considering the time at which it converges to a certain value with regard to the hydration reaction rate and the adsorbed water present in the hydration product or the water in the gel pores that does not contribute to the hydration reaction [13]. For the expansive additive, $V$ was set to 3.34 by considering a layer of hydration products and following the reasoning of Yamamoto et al., who described the expansion mechanism of expansive additives [18].

The time-dependent creep strain of the hydration product was applied according to the following equation. This is the same type of equation as that proposed by Lokhorst and van Breugel [14]:

$$
\varepsilon_{c, e}(t)=a \cdot \frac{(t-\tau)^{n}}{t_{0}} \cdot \sigma(\tau),
$$

where $\varepsilon_{c, e}(t)$ is the creep strain at the age $t, t-\tau$ is the time under the load $h, t_{0}$ is $1 \mathrm{~h}, \sigma(\tau)$ is the stress applied at the age $t, a$ is the creep constant $\left(\mathrm{mm}^{2} / \mathrm{N}\right)$, and $n$ is a constant (here, $n=0.3[14])$.

The creep constant $a$ of the hydration product of cement was set to $1.5 \times 10^{-5}$ based on the existing literature $[14,19]$. Although many studies have dealt with the material characteristics of hardening cement paste mixed with expansive additives, only a few have examined creep. The creep constant of hydration products produced by the hydration of only the expansive additive should be different from that of cement. Owing to the lack of sufficient data, however, this value was set to $2.1 \times 10^{-4}$ in this study based on previous experimental results [13] and other existing studies [12, 13], which showed that creep is slightly higher in expansive concrete than in normal concrete because the former expands through the generation of air gaps.

The activation energy for the temperature-dependent creep strain of the hydration products of cement and expansive additive was evaluated according to the model of Lokhorst and van Breugel [14] and Maruyama [15] by using the following equation:

$$
V(T)=\exp \left(\frac{Q}{R} \cdot \frac{T-T_{0}}{T \cdot T_{0}}\right)
$$

where $V(T)$ is a function describing the temperature effects, $R$ is the gas constant $(8.31 \mathrm{~J} / \mathrm{mol} \mathrm{K}), T$ is the temperature of the paste, and $T_{0}$ is the reference temperature $(293 \mathrm{~K})$. When $T=T_{0}, V(T)$ is 1 . The activation energy $Q$ for ordinary Portland cement was assumed to be $20,000 \mathrm{~J} / \mathrm{mol}$, which is a typical value $[14,15,20]$. In the case of the expansive additive, the activation energy was set to $43,496 \mathrm{~J} / \mathrm{mol}$, which was calculated with the following equation by using the $\mathrm{C}_{3} \mathrm{~S} / \mathrm{C}_{2} \mathrm{~S}$ ratio. This value can be calculated by considering the mineral

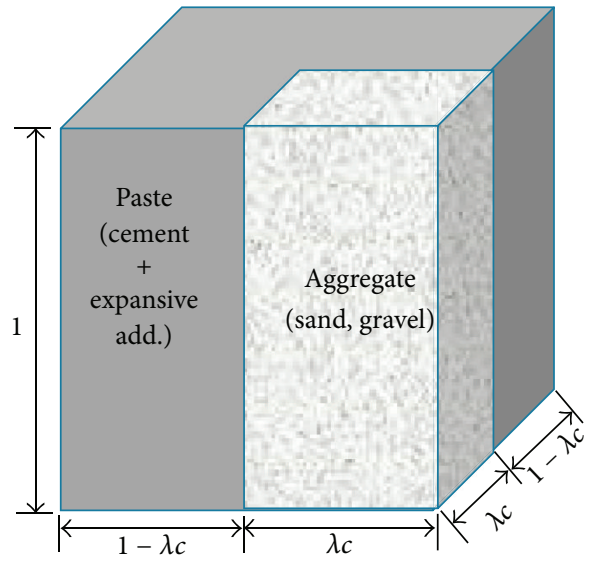

FIGURE 2: Composite model of mortar and concrete.

composition of the expansive additive, as presented in Table 1. Consider

$$
Q=-4070 \cdot\left(\frac{C_{3} S(\%)}{C_{2} S(\%)}\right)+38010,
$$

where $\mathrm{C}_{3} \mathrm{~S}$ and $\mathrm{C}_{2} \mathrm{~S}$ represent the ratio of $\mathrm{C}_{3} \mathrm{~S}$ and $\mathrm{C}_{2} \mathrm{~S}$ in the expansive additive and are calculated according to the following equation proposed by Bogue [21]:

$$
\begin{aligned}
\mathrm{C}_{3} \mathrm{~S}= & 4.0710 \cdot \mathrm{CaO}-7.6024 \cdot \mathrm{SiO}_{2}-1.4297 \cdot \mathrm{Fe}_{2} \mathrm{O}_{3} \\
& -6.7187 \cdot \mathrm{Al}_{2} \mathrm{O}_{3} \\
\mathrm{C}_{2} \mathrm{~S}= & 2.8675 \cdot \mathrm{SiO}_{2}-0.7544 \cdot \mathrm{C}_{3} \mathrm{~S} .
\end{aligned}
$$

The strain of the newly created elements varies because each element has a different stress history depending on the age; however, a uniform strain was considered for all elements owing to the redistribution of stress. Thus, the creep strain of the paste mixed with expansive additive can be expressed by (8) depending on the mixture rate of the expansive additive according to the balance of the creep strain of the cement and expansive additive parts:

$$
\varepsilon_{\text {paste }(C+\mathrm{EX})}=\varepsilon_{c(C)} \cdot C_{V(\%)}+\varepsilon_{c(\mathrm{EX})} \cdot \mathrm{EX}_{V(\%)},
$$

where $\varepsilon_{\text {paste }(C+\mathrm{EX})}$ is the creep strain of the cement paste mixed with expansive additive, $\varepsilon_{c(C)}$ is the creep strain of the cement part, $\varepsilon_{c(\mathrm{EX})}$ is the creep strain of the expansive additive part, $C_{V(\%)}$ is the volume mixing rate of cement, and $\mathrm{EX}_{V(\%)}$ is the volume mixing rate of expansive additive.

2.2. Composite Model for Mortar and Concrete. In order to extend the creep phenomenon to mortar and concrete, a composite model of paste and aggregate (fine and course aggregate) was used. The model shown in Figure 2 is based 

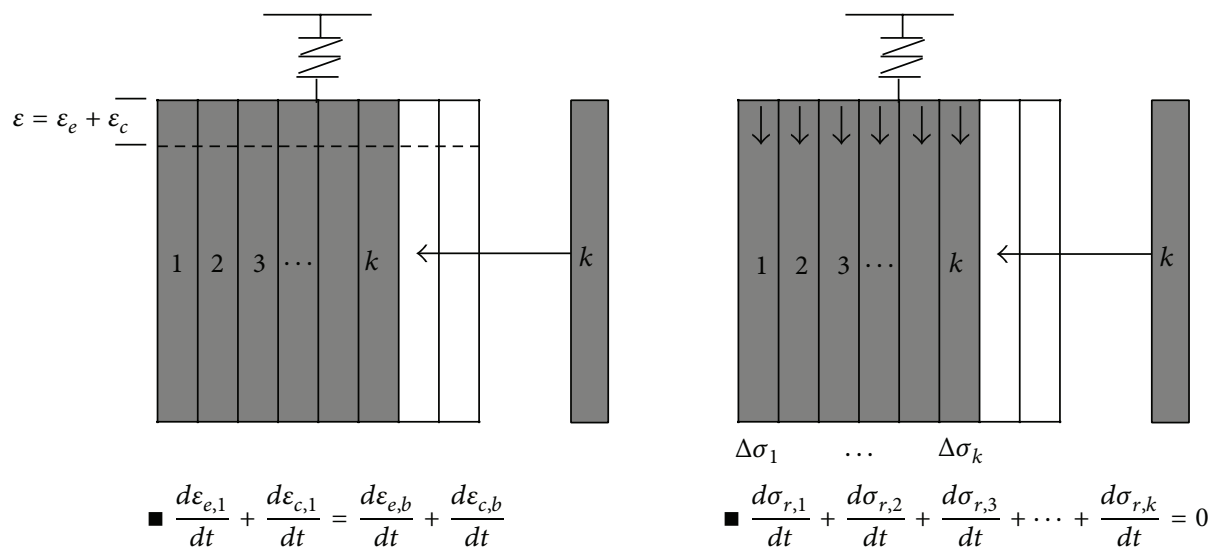

FIGURE 3: Strain and stress redistributions due to newly created elements.

on the assumption that aggregates do not experience timedependent strain. With this composite model, the stress load of the paste was considered to be redistributed to the aggregates because the aggregates should be under the same amount of time-dependent strain experienced by the paste. Thus, the time-dependent strain of mortar and concrete mixed with expansive additive can be calculated as follows by considering the strain attributed to the load shared by the aggregates as initiated by the paste strain:

$$
\begin{aligned}
& \varepsilon_{\text {mortar or concrete }(C+\mathrm{EX})} \\
& =\varepsilon_{\text {paste }(C+\mathrm{EX})} \\
& \quad \cdot\left[\left(\frac{\left(1-\lambda_{c}\right) \cdot E_{p} \cdot \lambda_{c}}{\lambda_{c} \cdot E_{\mathrm{agg}}+\left(1-\lambda_{c}\right) \cdot E_{p}}\right)+\left(1-\lambda_{c}\right)\right],
\end{aligned}
$$

where $\varepsilon_{\text {mortar or concrete }(C+\mathrm{EX})}$ is the creep strain of mortar or concrete mixed with expansive additive, $\varepsilon_{\text {paste(C+EX) }}$ is the creep strain of the paste mixed with expansive additive, $E_{p}$ is the elastic modulus of the paste mixed with expansive additive, and $E_{\text {agg }}$ is the elastic modulus of the aggregate. In addition, $\lambda_{c}$ is a constant related to the volume of the aggregates $V_{\text {agg }}$ relative to the unit volume; it can be expressed as $\lambda_{c}=\sqrt{V_{\mathrm{agg}}}$.

2.3. Estimation of Stress Redistribution. The stress redistribution was estimated by analyzing the modeled creep phenomenon. The required redistributed stress can be determined by solving $k$ linear equations when $k$ elements are considered, as shown in Figure 3. The sum of the creep strain and elastic strain over the time $t+\Delta t$ is the same for all elements, and the sum of the stresses does not change because of the generation of elements. Furthermore, if the creep strain follows the law of superposition and is proportional to the gel volume of the hydration products and the stress, the creep strain can be expressed as follows by applying the step-bystep method to each time increment:

$$
\begin{aligned}
\varepsilon_{\text {tot }}\left(t_{i+1}\right)= & \varepsilon_{\text {tot }}\left(t_{i}\right)+\frac{\Delta \sigma\left(\tau_{i}\right)}{E}+\sum_{j=1}^{i} a \cdot V\left(T_{i}\right) \cdot \Delta \sigma\left(\tau_{j}\right) \\
& \cdot\left[\left(t_{i+1}-\tau_{j}\right)^{n}-\left(t_{i}-\tau_{j}\right)^{n}\right] .
\end{aligned}
$$

Thus, the total strain can be calculated by summing the following three sets of terms according to (10):

(i) Total strain at time $t_{i}$.

(ii) Elastic strain $\Delta \varepsilon_{e}\left(t_{i}\right)$ attributed to the new stress increment $\Delta \sigma\left(\tau_{i}\right)$.

(iii) Creep strain increment $\Delta \varepsilon_{c}\left(t_{i}, \tau_{j}, T_{i}\right)$ generated by the stress increment $\Delta \sigma\left(\tau_{j}\right)$ in the next time interval $\left(t_{i}, t_{i+1}\right)$.

\section{Experiment}

3.1. Outline of the Experiment. Two types of specimens with a water/binder ratio of 0.50 were used: an expansive mortar with a $1: 3$ ratio of fine aggregate and binder, to which $5 \mathrm{wt} \%$ of an ettringite-gypsum type of expansive additives was mixed, and a normal mortar. Strength and shrinkage tests were conducted in order to evaluate the basic and modified properties of the mortars. Air content and slump flow tests were performed to determine the properties of the mortars when fresh. The specimens for the strength test were demolded on day 1 and cured in water $\left(20 \pm 2^{\circ} \mathrm{C}\right)$, after which the compressive and splitting tensile strengths were measured.

A $40 \mathrm{~mm} \times 40 \mathrm{~mm} \times 160 \mathrm{~mm}$ mold was used in the shrinkage test to measure the drying shrinkage with an embedded strain gauge. Drying shrinkage specimens were demolded on day 1 , and a portion of each specimen was completely sealed with aluminum tape in order to match the volume-to-surface area ratio (V/S) used in the ring test. They were then left in a moist room to dry (temperature: $20 \pm 2^{\circ} \mathrm{C}$; humidity: $60 \% \pm 5 \%$ ). 

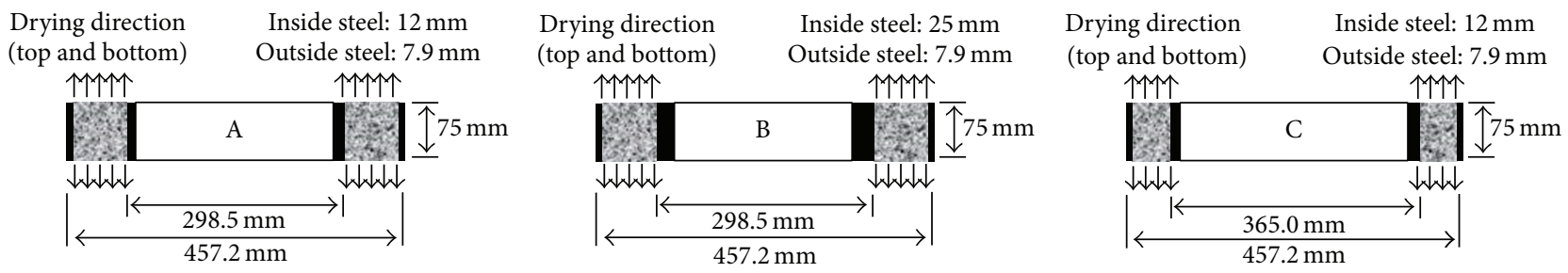

Figure 4: Overview of the ring test.

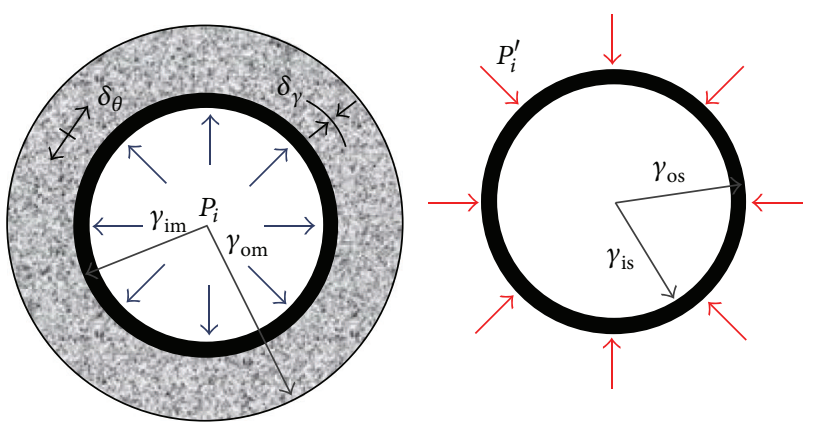

FIGURE 5: Stress distribution in the ring test.

In the ring-type constraint test, to induce drying shrinkage across the cross sections of the mortar rings in an even manner, as shown in Figure 4, the height of the ring-type constraint specimen was set to $75 \mathrm{~mm}$ instead of $152 \mathrm{~mm}$ as prescribed by AASHTO PP34-98 [22]. Tests were conducted with ring-type constraint specimens at three levels: $\mathrm{A}, \mathrm{B}$, and C. This was to assess the strain and stress under different constraints, such as different inner ring thicknesses and diameters. The inner steel rings were left free of any surface treatment, such as oil or other lubricants. After the mortar was deposited, the surfaces of the mortar rings were sealed with vinyl sheets in order to prevent fast drying caused by moisture evaporation. After 1 day, the bottom forms were removed to allow only the top and bottom surfaces of the mortar to dry. Three strain gauges $(h=37.5 \mathrm{~mm})$ were installed on the inner steel rings, and the constrained strain was assessed with a datalogger while the rings remained in the constant temperature and humidity room (temperature: $20 \pm 2{ }^{\circ} \mathrm{C}$; humidity: $60 \% \pm 5 \%$ ).

3.2. Calculation of the Constrained Stress in the Ring Test. Figure 5 shows a conceptual picture of the stress distribution in the ring test. The conversion of the steel strain to the tensile strength of the mortar is based on the assumption of an arbitrary interface pressure $P$ of the same size but opposite in direction. This interface pressure $P$ was attributed to the shrinkage of the mortar and constraint of the steel rings. If the mortar shrinks evenly and linearly across the whole cross section, the circumferential stress $\sigma_{\theta}$ of a specimen can be defined as follows [23-25]:

$$
\sigma_{\theta}=\frac{r_{\mathrm{im}}^{2} \cdot P}{r_{\mathrm{om}}^{2}-r_{\mathrm{im}}^{2}}\left[1+\frac{r_{\mathrm{om}}^{2}}{r^{2}}\right]
$$

where $r_{\text {im }}$ and $r_{\text {om }}$ are the inner and outer radii, respectively, of the mortar and $r$ is an arbitrary value in the direction of the axis. In addition, the maximum constrained stress in the circumferential direction occurs at the border between the inner steel ring and mortar $\left(r=r_{\text {im }}\right)$. This can be calculated by using the following equation:

$$
\sigma_{\theta_{i}}=\frac{P_{i} \cdot\left(r_{\mathrm{im}}^{2}+r_{\mathrm{om}}^{2}\right)}{r_{\mathrm{om}}^{2}-r_{\mathrm{im}}^{2}}, \quad r=r_{\mathrm{im}}
$$

The pressure $P_{i}$ on the inner steel ring acts as the external pressure of the same magnitude but in the opposite direction. It can be expressed by using the following equation for the measured strain of the inner steel ring:

$$
P_{i}=\frac{\left(r_{\mathrm{os}}^{2}-r_{\mathrm{is}}^{2}\right)}{2 r_{\mathrm{os}}^{2}} \cdot \sigma_{\theta, \mathrm{st}}=\frac{\left(r_{\mathrm{os}}^{2}-r_{\mathrm{is}}^{2}\right)}{2 r_{\mathrm{os}}^{2}} \cdot E_{\mathrm{st}} \cdot \varepsilon_{\mathrm{st}}, \quad r=r_{\mathrm{is}},
$$

where $\sigma_{\theta, \text { st }}$ is the stress on the inner steel ring in the circumferential direction, $E_{\mathrm{st}}$ and $\varepsilon_{\mathrm{st}}$ are the elastic modulus and constrained strain, respectively, and $r_{\text {is }}$ and $r_{\text {os }}$ are the inner and outer radii, respectively, of the inner steel ring.

Therefore, if (13) is substituted into (12), the maximum constrained stress of the mortar can be obtained as follows:

$$
\sigma_{\theta i \max }=\frac{\left(r_{\mathrm{os}}^{2}-r_{\mathrm{is}}^{2}\right)}{2 r_{\mathrm{os}}^{2}} \cdot \frac{\left(r_{\mathrm{im}}^{2}+r_{\mathrm{om}}^{2}\right)}{\left(r_{\mathrm{om}}^{2}-r_{\mathrm{im}}^{2}\right)} \cdot E_{\mathrm{st}} \cdot \varepsilon_{\mathrm{st}} .
$$

3.3. Test Results. Table 2 lists the test results for the slump flow, air content, and strength. When the expansive additive was mixed in, the workability and air content did not change considerably. The expansive mortar had lower compressive strength and splitting tensile strength than the normal mortar, but these differences were negligible. In other words, the expansive additive had minimal effect in terms of the fresh and strength properties.

Figure 6 shows the drying shrinkage results. The drying shrinkage of the normal mortar was $941 \mu$ at day 56, while that of the expansive mortar was $866 \mu$. The drying shrinkage decreased in the expansive mortar. However, these results did not consider the effect of expansion at an early age from the expansive additive. Thus, a reduction of $100 \mu$ from drying shrinkage due to the early expansion of the expansive additive $[26,27]$ was considered along with the drying shrinkage strain under unconstrained conditions. Then, using the 
TABLE 2: Fresh and strength properties.

\begin{tabular}{|c|c|c|c|c|c|c|c|c|}
\hline \multirow[t]{2}{*}{ Type } & \multirow{2}{*}{$\begin{array}{l}\text { Slump flow } \\
\quad(\mathrm{cm})\end{array}$} & \multirow{2}{*}{$\begin{array}{l}\text { Air content } \\
\quad(\%)\end{array}$} & \multicolumn{3}{|c|}{ Compressive strength $\left(\mathrm{N} / \mathrm{mm}^{2}\right)$} & \multicolumn{3}{|c|}{$\begin{array}{l}\text { Splitting tensile strength } \\
\qquad\left(\mathrm{N} / \mathrm{mm}^{2}\right)\end{array}$} \\
\hline & & & 7 days & 14 days & 28 days & 7 days & 14 days & 28 days \\
\hline $\mathrm{N}$ & 18.5 & 5.6 & 21.75 & 34.39 & 45.61 & 2.81 & 3.19 & 3.64 \\
\hline EX & 17.5 & 5.1 & 21.06 & 33.12 & 47.13 & 2.80 & 3.27 & 3.59 \\
\hline
\end{tabular}

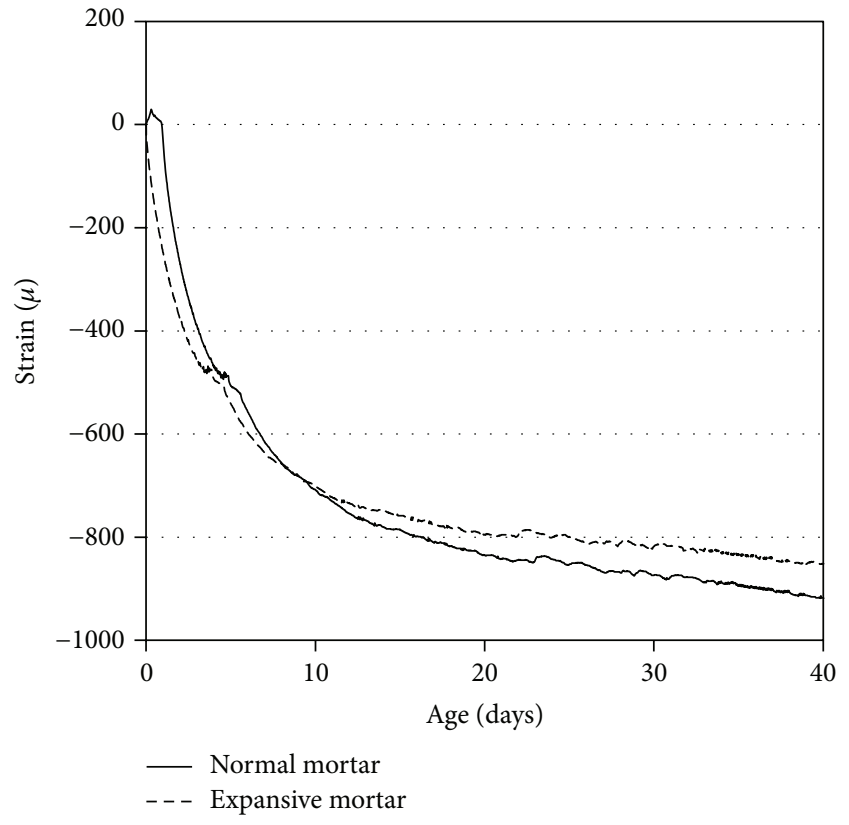

FIGURE 6: Results of drying shrinkage.

expansive additive was found to reduce the drying shrinkage by approximately $18.6 \%$.

Figures 7 and 8 show the constrained strains and stresses of the inner steel rings. The strains decreased because of the compressive force due to the early expansion of the expansive additive. However, the strains of the normal mortar abruptly increased with the increase in nonconstrained shrinkage; cracking occurred immediately after the maximum strain was attained. In addition, the admixture of expansive additive decreased the maximum pressure on the inner steel ring, which in turn decreased the constrained stress and delayed the cracking time of the mortar.

The maximum constrained stress tended to decrease as the thickness and diameter of the inner ring were increased. This was probably because even when the constrained load on the interface remained constant, the thickness and diameter of the inner steel ring increased with the degree of constraint. That is, as the inner steel ring became thicker, it was not strained, and the amount of relaxing shrinkage increased from an early age.

Overall, the admixture with expansive additive delayed cracking by 17-28 days. Thus, the use of the expansive additive was confirmed to reduce the tensile stress and crack resistance.

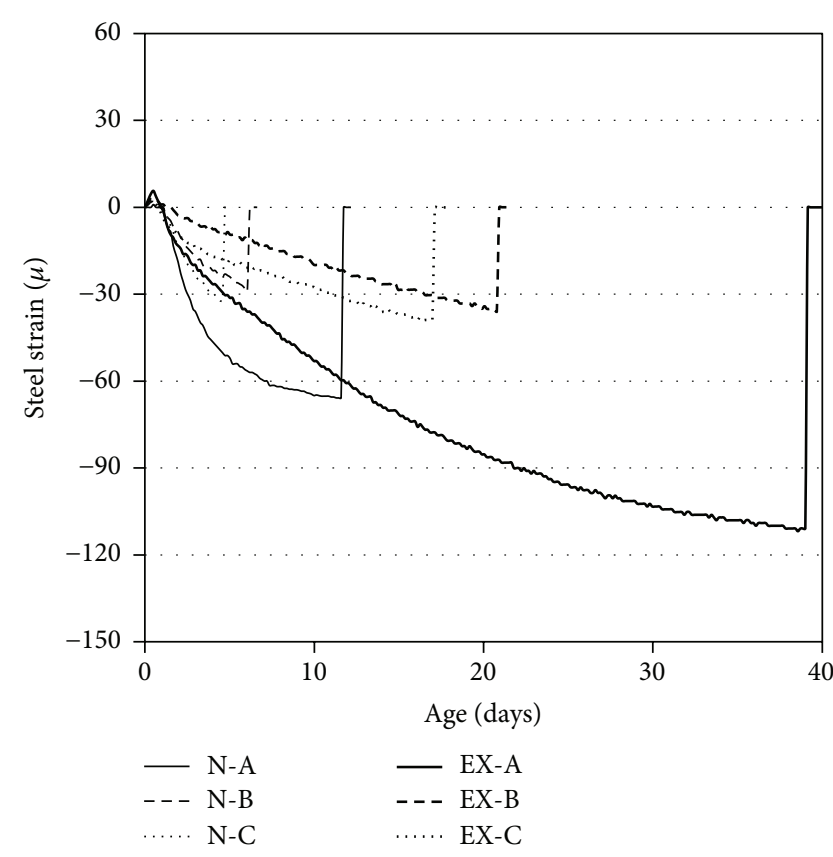

FIGURE 7: Constrained strains of the inner rings.

\section{Estimation of the Constrained Stress by Creep Analysis}

4.1. Hydration Reaction Rate. For the analysis of the creep model, the hydration rate $\alpha$ is the parameter required to obtain the outermost radius of the cement and expansive additive particles according to (3). Here, the hydration reaction rate was defined as the amounts of cement and expansive additive that underwent reactions compared to their corresponding total amounts. In order to determine this rate, a value calculated from using the net calorific value was applied. The calorific value was obtained by measuring the calories generated during the hydration process with a multimicro calorimeter (MMC-511 SV). When the water/cement and water/expansive additive ratios were 0.50 , the net calorific values were 437.53 and $887.12 \mathrm{~J} / \mathrm{g}$ for the cement and expansive additive, respectively. Figure 9 shows an example calculation for the rate of heat liberation and degree of hydration. The figure confirms that the hydration reaction rate for the expansive additive was higher than that for cement at all ages owing to the increased exothermic peak from the rapid reaction of the expansive additive at an early age. The experimental data were used in the creep analysis.

4.2. Elastic Modulus. The elastic modulus for creep analysis was obtained by using (15) based on previous modeling 


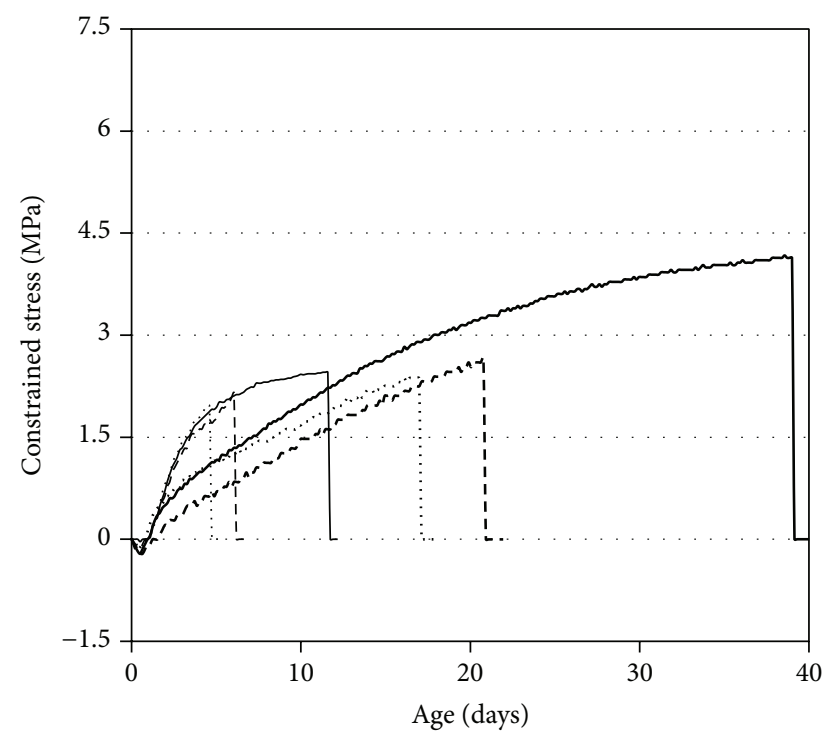

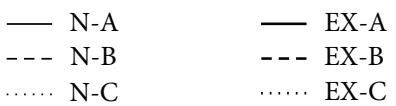

FIgURE 8: Constrained stresses of the inner rings.

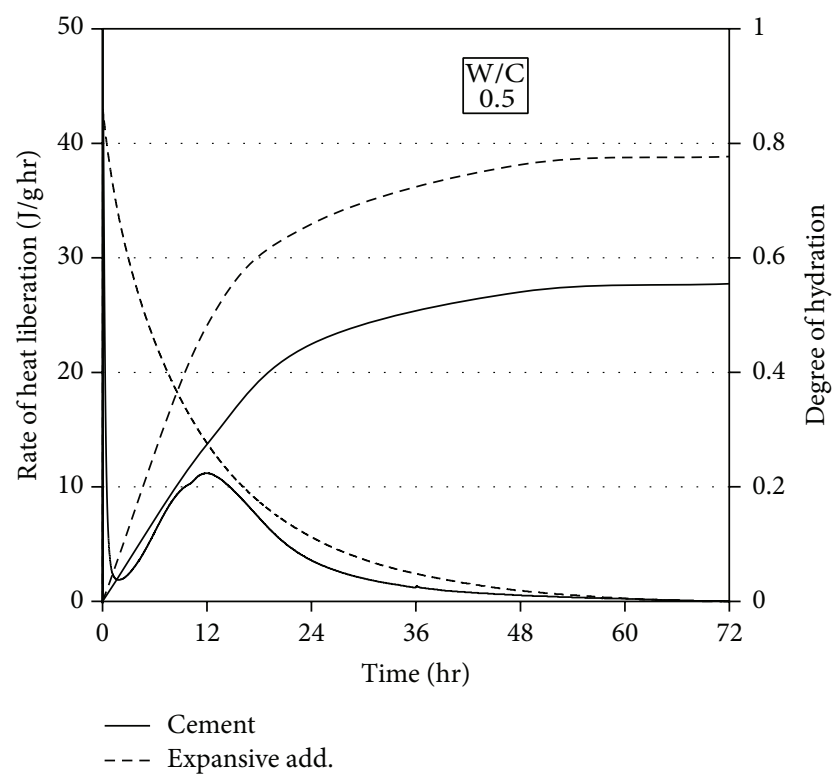

FIgure 9: Rate of heat liberation and degree of hydration of the cement and expansive additives.

work [12, 28] based on Maruyama's C-CBM model [15]. This equation indicates that the outer product has a lower density than the inner product, as shown in Figure 10. However, the phenomenon of densification with age was considered through the large expansion in terms of space based on the effective contact area $A_{\text {ceff }}$ :

$$
\begin{aligned}
& E_{\text {paste(C,EX) }} \\
& =\frac{1}{\lambda_{p} /\left(\lambda_{p} \cdot E_{\text {gel }(C, \mathrm{EX})}+\left(1-\lambda_{p}\right) \cdot E_{C, \mathrm{EX}}\right)+\left(1-\lambda_{p}\right) / E_{\text {gel(C,EX })}} \\
& \quad \cdot A_{\text {ceff }},
\end{aligned}
$$

where $E_{\mathrm{paste}(C, \mathrm{EX})}$ is the elastic modulus of the cement paste or expansive paste, $E_{C, E X}$ is the elastic modulus of the unhydrated cement or expansive additive, $E_{\mathrm{gel}(C, \mathrm{EX})}$ is the elastic modulus of the hydration product, and $A_{\text {ceff }}$ is the effective contact area. In addition, $\lambda_{p}$ is a constant related to the volume of the unhydrated cement or expansive additive $V_{C, E X}$ relative to the unit volume and can be expressed as $\lambda_{p}=\sqrt{V_{C, E X}}$.

With the model, $E_{C, E X}$ and $E_{\text {gel(C,EX) }}$ had values of 50 and $25 \mathrm{GPa}$, respectively. These values were taken from the results of Maruyama [15], who determined these values by referring to the values of 40 and $20 \mathrm{GPa}$ suggested by Hua et al. [29] and 60 and $30 \mathrm{GPa}$ suggested by Lokhorst and van Breugel [14]. In the case of the expansive additive, the value for cement was applied because sufficient data could not be found.

The elastic modulus of the paste mixed with the expansive additive can be expressed by (16). It depends on the mixture ratio of the expansive additive by balancing the elastic modulus of the required cement part and elastic modulus of the expansive additive part:

$$
E_{\text {paste(C+EX) }}=E_{\text {paste(C) }} \cdot C_{V(\%)}+E_{\text {paste(EX) }} \cdot \mathrm{EX}_{V(\%)},
$$

where $E_{\text {paste(C+EX) }}$ is the elastic modulus of the cement paste mixed with the expansive additive, $E_{\text {paste(C) }}$ is the elastic modulus of the cement part, $E_{\text {paste(EX) }}$ is the elastic modulus of the expansive additive part, $C_{V(\%)}$ is the volume mixing rate of the cement, and $\mathrm{EX}_{V(\%)}$ is the volume mixing rate of the expansive additive.

In order to extend this equation to the elastic moduli of mortar and concrete, a composite model of the paste and aggregate was used as a creep model. The aggregate was assumed to exhibit no creep behavior. Hence, the paste dominates the behavior of the mortar or concrete. Therefore, the aggregate has a resistor function without affecting the behavior of the paste. If a composite model for the aggregate and paste is assumed, the elastic modulus of the mortar or concrete can be expressed by

$$
\begin{aligned}
& E_{\text {mortar or concrete }(\mathrm{C}+\mathrm{EX})} \\
& =\frac{1}{\lambda_{c} /\left(\lambda_{c} \cdot E_{\text {paste(C+EX) }}+\left(1-\lambda_{c}\right) \cdot E_{\text {agg }}\right)+\left(1-\lambda_{c}\right) / E_{\text {paste }(C+\mathrm{EX})}},
\end{aligned}
$$

where $E_{\text {mortar or concrete( } C+\mathrm{EX})}$ is the elastic modulus of the concrete mixed with the expansive additive, $E_{\text {paste }(\mathrm{C}+\mathrm{EX})}$ is the elastic modulus of the cement paste mixed with the expansive additive, and $E_{\mathrm{agg}}$ is the elastic modulus of the aggregate. In addition, $\lambda_{c}$ is a constant related to the volume of the aggregates $V_{\text {agg }}$ relative to the unit volume and can be expressed as $\lambda_{c}=\sqrt{V_{\mathrm{agg}}}$.

4.3. Estimation of the Constrained Stress. The stress change in the expansive mortar under the constrained condition was estimated by considering the modeled creep phenomenon described in Section 2. The estimated stress was compared with the experimental results of the ring test described in 

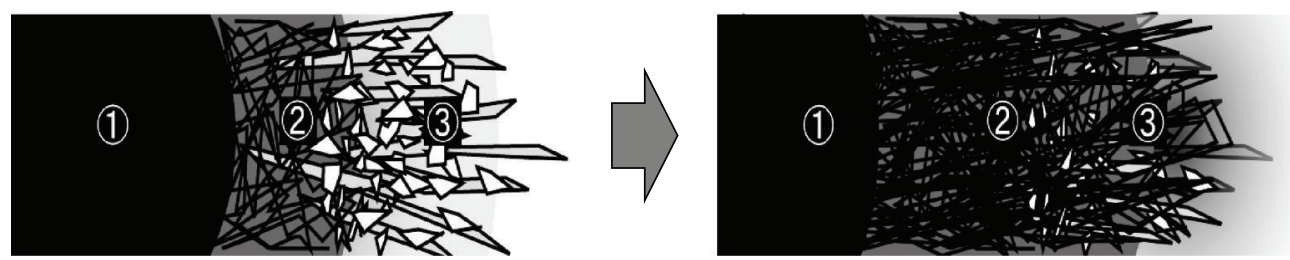

(1) Unhydrated cement and expansive additives

(2) Inner product

(3) Outer product

FIGURE 10: Density changes in the hydration product during hydration [6].

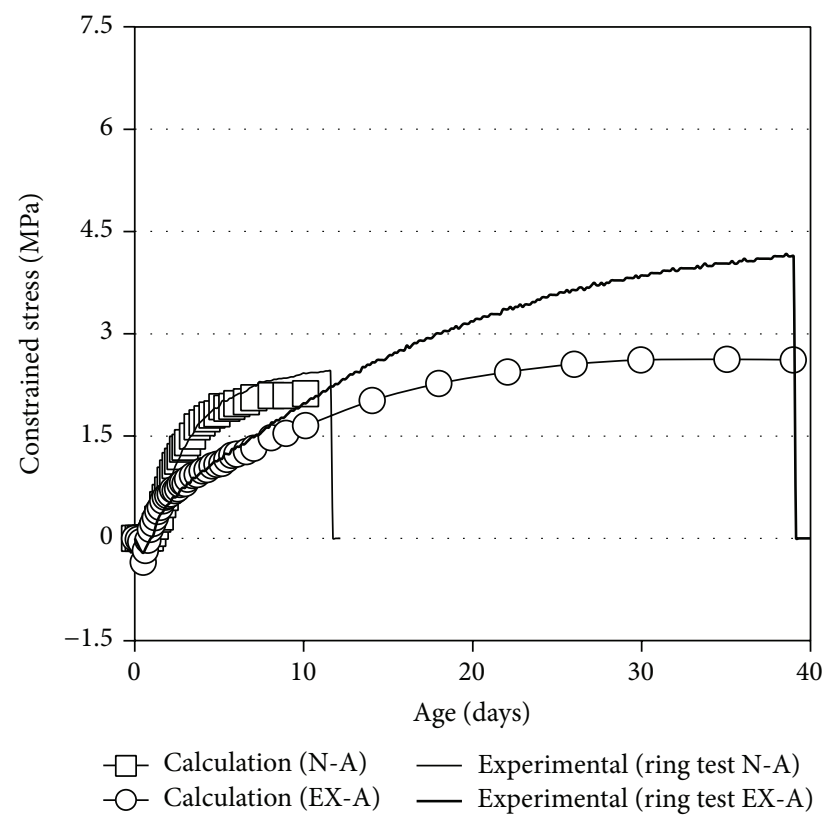

Figure 11: Calculation of the constrained stress by the creep model (Specimen A).

Section 3 to validate the stress prediction technique using the model.

If the mortar poured into the ring object is assumed to show linear elastic behavior under various constraints, the pressure applied by the constraint of the steel and that applied to the mortar become identical. Thus, by calculating the pressure applied to the interface of the inner steel ring and mortar with the creep model by using the deformation measured from the inner steel ring, the maximum tensile stress applied in the direction of the circumference of the mortar can be calculated. Figures 11-13 show the maximum tensile stress according to the ring test and calculated with the creep model under various constraints. The results of the ring test were predicted under the assumption that the mortar poured to the ring exhibits linear elastic behavior, and the actual behavior of mortar differed from the stress applied to the ring object. Thus, the maximum tensile stress predicted for objects, including object $B$, differed slightly from the maximum tensile stress according to the ring test.

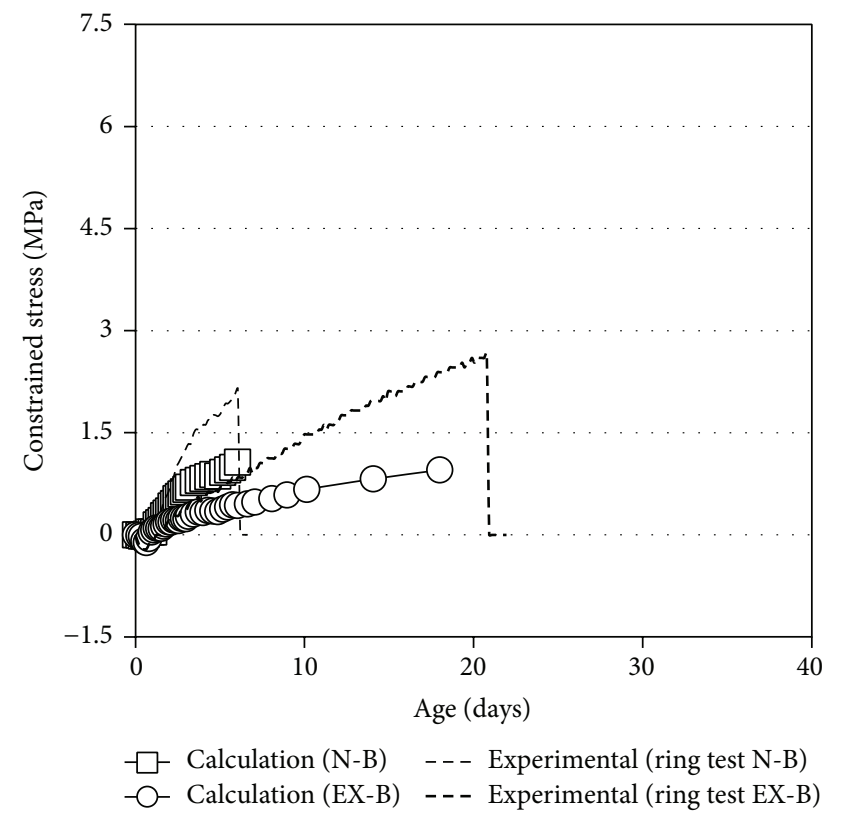

FIGURE 12: Calculation of the constrained stress by the creep model (Specimen B).

However, the results confirmed that the progression of stress in ordinary mortar and expansive mortar with age can be predicted to some degree.

\section{Conclusions}

A model was developed for the creep of hardening cement paste mixed with expansive additive to control cracking. The constrained stress of expansive mortar was estimated by using the modeled creep to calculate the changes in the stress under constraints. The results of the study can be summarized as follows:

(1) The hydration products of the expansive additive and cement were considered under the assumption that these products cause creep. The creep of hardening cement paste mixed with expansive additive was modeled by considering the redistribution of stress between the newly generated hydration products and the already existing hydration product that was 


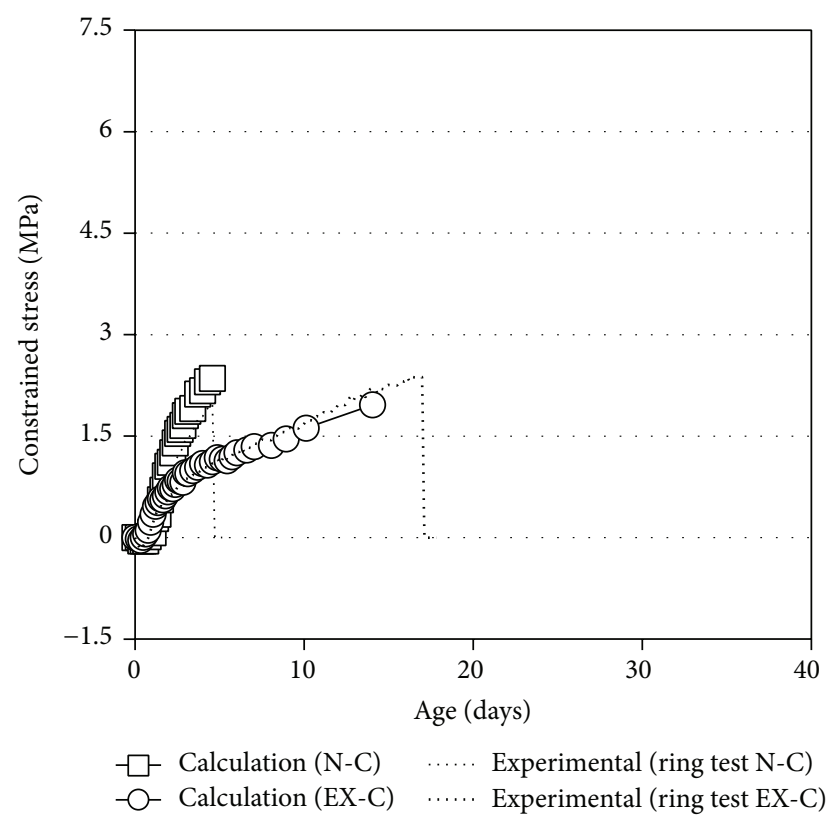

FIGURE 13: Calculation of the constrained stress by the creep model (Specimen C).

bearing the stress as well as the balance between the expansive additive and hydration products of cement.

(2) If the creep deformation is proportional to the stress and the gel volume of the hydration products, the law of superposition can be applied. This was used to predict the stress development by applying the stepby-step method for each time increment.

(3) For the ring test, the maximum tensile stress applied to the inner steel ring was predicted through a creep analysis based on the measured deformation of the inner steel ring and under the assumption that the mortar in the ring exhibits linear elastic behavior. The results confirmed that the progression with age of stress in ordinary mortar and expansive mortar can be predicted to some degree.

\section{Competing Interests}

The authors declare that they have no competing interests.

\section{References}

[1] AIJ (Architectural Institute of Japan), Recommendations for Practice of Crack Control in Reinforced Concrete Buildings (Design and Construction), AIJ, 2006.

[2] ACI, "Standard practice for the use of shrinkage compensating concrete," ACI Manual of Concrete Practice ACI 223R-98, 1993.

[3] JCI C77, Proceedings of JCI Symposium on Evaluation of Concrete Shrinkage and Its Effect, Japan Concrete Institute, Tokyo, Japan, 2010.

[4] ACI Committe, Guide for Modeling and Calculating Shrinkage and Creep in Hardened Concrete, ACI Committe 209, 2008.
[5] R. I. Gilbert, Time-Effects in Concrete Structures, Elsevier Science, Amsterdam, The Netherlands, 1988.

[6] A. M. Neville, Creep of Concrete: Plain, Reinforced and PreStressed, North Holland Publishing Company, Amsterdam, Netherlands, 1970.

[7] M. Morioka, Hydration and material design of cement-based expansive additive [Ph.D. thesis], Tokyo Institute of Technology, Tokyo, Japan, 1999.

[8] P. Carballosa, J. L. García Calvo, D. Revuelta, J. J. Sánchez, and J. P. Gutiérrez, "Influence of cement and expansive additive types in the performance of self-stressing and self-compacting concretes for structural elements," Construction and Building Materials, vol. 93, pp. 223-229, 2015.

[9] T. Higuchi, M. Eguchi, M. Morioka, and E. Sakai, "Hydration and properties of expansive additive treated high temperature carbonation," Cement and Concrete Research, vol. 64, pp. 11-16, 2014.

[10] R. Sahamitmongkol and T. Kishi, "Tensile behavior of restrained expansive mortar and concrete," Cement and Concrete Composites, vol. 33, no. 1, pp. 131-141, 2011.

[11] H. G. Choi, M. Tsujino, T. Noguchi, and R. Kitagaki, "Application to buildings and cracking control effects of expansion concrete," Cement Science and Concrete Technology, vol. 67, pp. 583-596, 2014.

[12] H. G. Choi, A study on the macro prediction of shrinkagereduction behavior in concrete using expansive additives [Ph.D. thesis], The University of Tokyo, Tokyo, Japan, 2013.

[13] H. G. Choi, M. K. Lim, H. S. Choi, T. Noguchi, and R. Kitagaki, "Modelling of creep of concrete mixed with expansive additives," Magazine of Concrete Research, vol. 67, no. 7, pp. 335348, 2015.

[14] S. J. Lokhorst and K. van Breugel, "Simulation of the effect of geometrical changes of the microstructure on the deformational behaviour of hardening concrete," Cement and Concrete Research, vol. 27, no. 10, pp. 1465-1479, 1997.

[15] I. Maruyama, Time dependent property of cement based materials on the basis of micro-mechanics [Ph.D. thesis], The University of Tokyo, Tokyo, Japan, 2003.

[16] I. Maruyama, T. Noguchi, P. Lura, and K. van Breugel, "Calculation of self-induced stress in early-age concrete using creep and relaxation model," in Proceedings 1st FIB Congress Concrete structures in the 21st Century, vol. 1, Session 9, pp. 215-221, Osaka, Japan, 2002.

[17] T. C. Powers and T. L. Brownyard, "Studies of the physical properties of hardened Portland cement paste," Journal of the American Concrete Institute (Proceedings), vol. 43, no. 9, pp. 469-504, 1974

[18] K. Yamamoto, M. Morioka, E. Sakai, and M. Daimon, "Expansion mechanism of cement added with expansive additive," Concrete Research and Technology, vol. 14, no. 3, pp. 23-31, 2003.

[19] K. van Breugel and S. J. Lokhorst, "The role of microstructural development on creep and relaxation of hardening concrete," in Proceedings of the International RILEM Conference on Early Age Cracking in Cementitious Systems, pp. 3-10, RILEM Publications, 2003.

[20] M. Taniguchi, O. Katsura, and Y. Hama, "Influence of type of cement on temperature dependency of the strength development of mortar," Proceedings of the Japan Concrete Institute, vol. 31, no. 1, pp. 415-420, 2009.

[21] R. H. Bogue, The Chemistry of Portland Cement, Reinhold, New York, NY, USA, 1955. 
[22] AASHTO (American Association of State Highway and Transportation Officials), Standard Practice for Estimating the Crack Tendency of Concrete, AASHTO, 1998.

[23] A. C. Ugural and S. K. Fenster, Advanced Strength and Applied Elasticity, Prentice Hall PTR, Upper Saddle River, NJ, USA, 3rd edition, 1995.

[24] A. B. Hossain and J. Weiss, "Assessing residual stress development and stress relaxation in restrained concrete ring specimens," Cement and Concrete Composites, vol. 26, no. 5, pp. 531540, 2004.

[25] W. J. Weiss and S. Fergeson, "Restrained shrinkage testing. The impact of specimen geometry on quality control testing for material performance assessment," in Concreep 6, Creep, Shrinkage, and Durability Mechanic of Concrete and Other Quasi-Brittle Materials, F. J. Ulm, Z. P. Bazant, and F. H. Wittman, Eds., pp. 645-651, Elsevier, Cambridge, Mass, USA, 2001.

[26] H. Hashida, T. Kikuchi, M. Tsujino, and H. Tanaka, "Low shrinkage concrete with both expansive additive and limestone aggregates (part3 initial expansion force and shrinkage reducing effect," in Proceedings of the Summaries of Technical Papers of Annual Meeting, pp. 927-928, Architectural Institute of Japan, 2010.

[27] H. Momose and T. Kanda, "Quantitative estimation of drying shrinkage reduction effects due to an expansive additive," Journal of Structural and Construction Engineering, vol. 76, no. 666, pp. 1367-1373, 2011.

[28] H. G. Choi and T. Noguchi, "Modeling of mechanical properties of concrete mixed with expansive additive," International Journal of Concrete Structures and Materials, vol. 9, no. 4, pp. 391-399, 2015.

[29] C. Hua, A. Ehrlacher, and P. Acker, "Analyses and models of the autogenous shrinkage of hardening cement paste II. Modelling at scale of hydrating grains," Cement and Concrete Research, vol. 27, no. 2, pp. 245-258, 1997. 

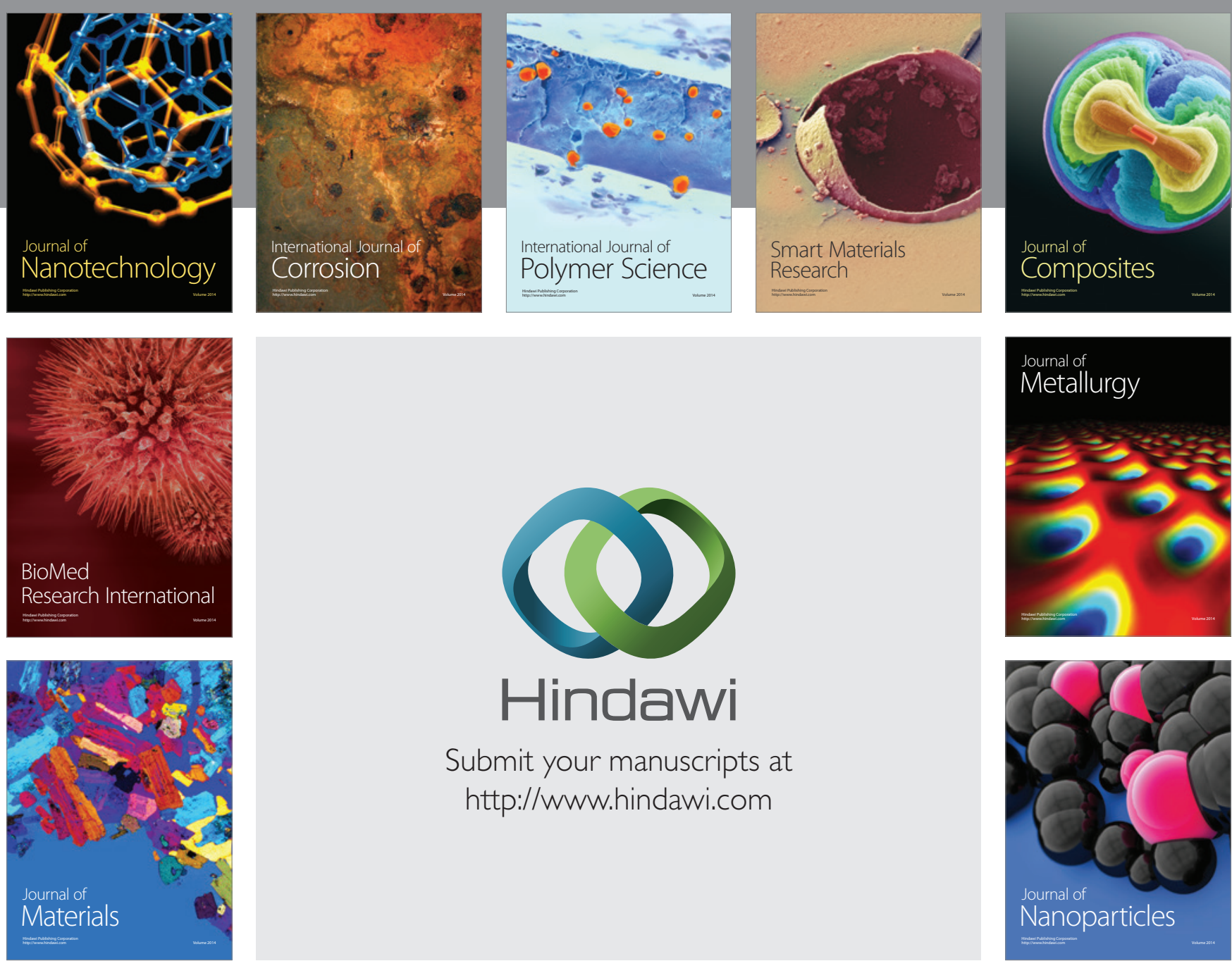

\section{Hindawi}

Submit your manuscripts at

http://www.hindawi.com

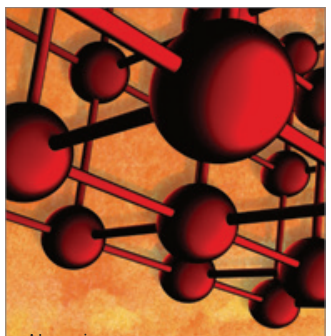

Materials Science and Engineering
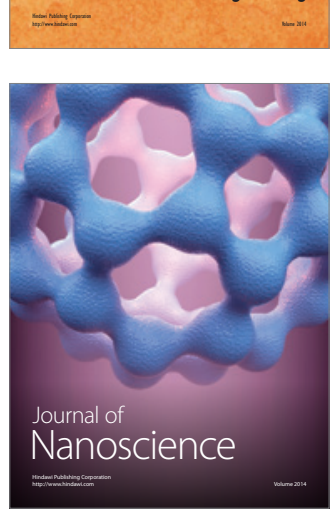
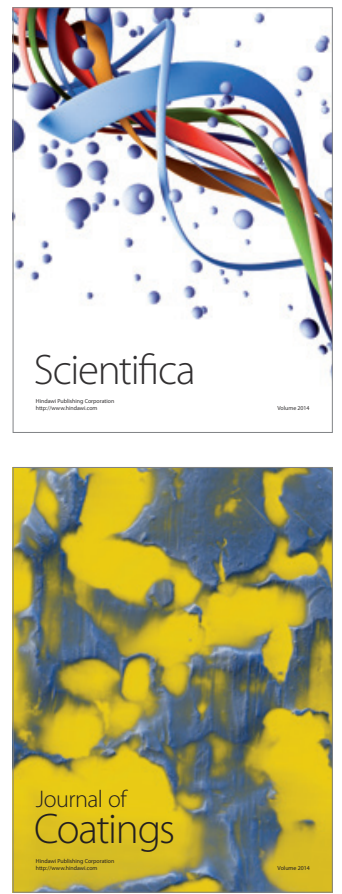
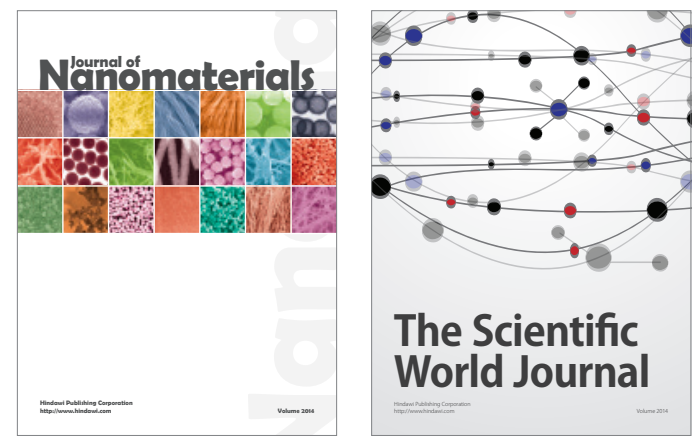

The Scientific World Journal
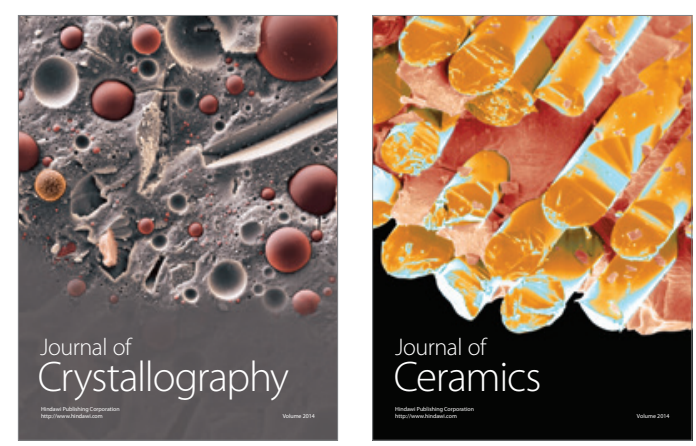
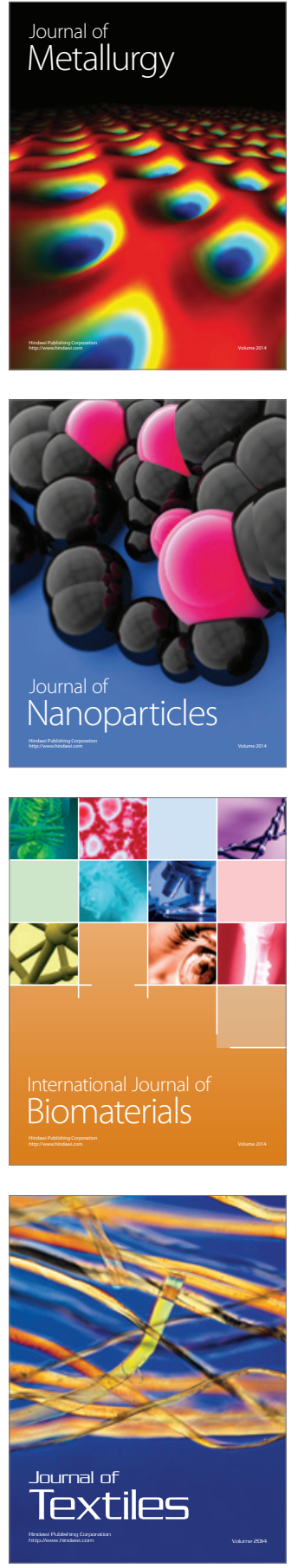